I do not lay claim to any new discovery with veratrum viride. I have used it freely in some very severe cases of typhoid fever ; ard in a bush practice like this good nursing is only present in one's dreams, and the same remark will apply to ice and other sick comforts. Added to this, for three consecutive days recently the shade temperature went up to $109^{\circ}, 1125^{\circ}$, and $111^{\circ} \mathrm{F}$, and yet veratrum viride in my hands has never failed to do good. I would urge a more extended use of it in the interest of patients who may be suffering from this very fatal disease, typhoid fever.

Tungamah, Victoria, Australia.

\section{ON CERTAIN EFFECTS OF TOBACCO SMIKING.} By A. G. Auld, M.D.

THE practice of tobacco smoking is so general amongst the male sex that it is very commonly overlooked in conputing the causes of disease. And this seems somewhat strange when it is considered that one of the most virulent known poisons should be continually at work in the systema poison, moreover, whose physiological reactions have never been accurately determined. A vast number doubtless tolerate the poison well ; by a goodly number tolerance is less easily acquired--that is to say, it is acquired at greater expense to the system; whilst there are others by whom tolerance is almost impossible of attainment. It is my growing impression that tobacco is responsible for a variety of functional derangements which there is no reason to aver cannot terminate in organic disease. Some of these are already well known, and easy of detection to their true source; but there are others less so, and it is my present object to notify two of them.

The first is albuminuria. Since the routine examination. of the urine by careful chemical testing has come more intc vogue, small quantities of albumen are frequently detected in the urine of apparently healthy persons. Having systematically examined the urine in hundreds of cases for a number of years, I am convinced that the slightest trace of albumen in the urine is pathological. It is, however, frequently induced by preventable causes, and one of these is chronic poisoning by nicotine. I do not observe any mention of tobacco smoking in this connexion in Dr. Grainger Stewart's work on Albuminuria, or, indeed, in any other writings on this subject; but I have certainly traced the disorder in a few cases entirely, and in others partially, to the habit in question.

The other affection pertains to the neuro-muscular system. It consists in localised fibrillary twitchings, something similar to what is observed in progressive muscular atrophy, and perfectly distinet from tremor. Charcot states that a similar phenomenon is occasionally found in hypochondriasis. The twitchings are often excessive, and occur most frequently about the trunk and upper arms. Besides its action on the centres, it is probable that the poison acts directly on the nerve termini in the muscles, as it is found that when tetanus of the inspiratory muscles succeeds to nicotine poisoning, section of the vagi is ineffectual to prevent it. According to Kölliker, the muscular irritability remains unaffected by nicotine.

It remains to say that when such symptoms as the above are found in association with tobacco smoking, it will not suffice merely to indulge less in the practice. To effect a cure, tobacco in every shape must be entirely dispensed with. It is unsuited to the constitution, and its abolition should be permanent.

cllasgow.

\section{ON CIRCUMCISION.}

By W. W. STNCLAIR,

RESIDENCY SURGEON OF SELAUGOR, MALAY, PROTECTED NATIVE STATES.

THE necessity of circumcision in many cases, and the benefits derived therefrom being more recognised in modern surgery, have brought this ancient operation more in to vogue at the present day. Still, the appliances for facilitating this operation are few, and beyond the description of it in "Erichsen"s Surgery" the subject is passed over very casually by the majority of writers of surgical works, or,

on the other liand, made rather complicated. The accompanying woodent (Fig. 1) represents the original "Sapit Bersunah," or circumcising instrument of the Malays, and has been in use for very many years in Rio and the Malay peninsula. It consists of two strips of mirabo wood, held together by four rottan rings, two being at each end, and hollowed out at its broad centre into an oval concavity. The dotted lines represent the instrument open, the two rottan rings being withdrawn. While open, the glans penis is laid in the concavity and the skin drawn through, but great care is taken not to injure the frenum in any way. It is left protected in the hollow with the glans; the instrument is then closed like a clamp and

FIG. 1.

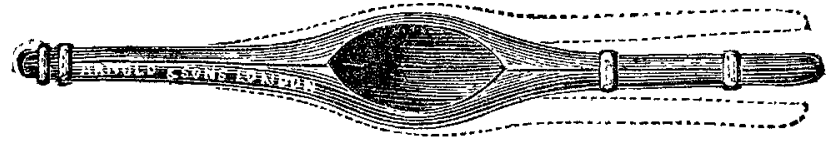

fastened by the rottan rings being passed over and up the ends; the skin is then removed by the slicing action of a sharp knife (preferably a good English razor) drawn through the skin with the edge close to the wood. The portion of skin removed should have the shape of a jelly bag, the only dressing used being a little native tobacco or pounded guava leaves; but the Imams prefer iodoform or carbolic acid when they can get them. This operation is generally performed when the child is about eight years of age, by the Imâm (Mahomedan priest), but can be performed at any age, this being one of the requirements when embracing the Mahomedan faith. In the case of a

FiG. 2.

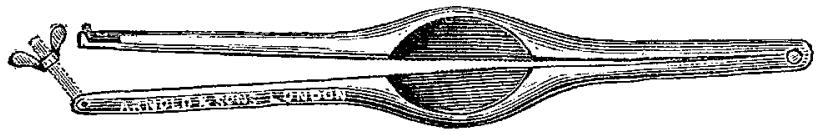

female the clamp is not required; only one-eighth of an inch is nipped off the end of the clitoris, and this is generally done by an old woman of the village. Fig. 2 represents a plated steel clamp made by Messrs. Arnold and Sons of London, which is an improvement on the wooden instrument (Fig, 1), which was made for and at the suggestion of Haji Rajah Boh of Selaugor, I have found the operation with this clamp so simple, rapid, clean and safe, no stitching of the mucous membrane or tying of vessels being required, that I have no hesitation in recommending this instrument, with the Malay operation, to the profession. Selaugor, Malay.

\section{A CURIOUS COMPLICATION OF PUERPERAL ECLAMPSIA; UNCONSCIOUSNESS FOR EIGHTY-FOUR HOURS; RECOVERY.}

BY RAINSFoRd F. GILL, M.B., M.R.C.S.

I wAs called to attend a primipara, aged twenty-one, at about 10 A.M. one Sunday, labour pains having just begun. She appeared rather puffy about the face, and there was considerable pallor, but no headache was complained of, and everything appeared normal. I was obliged to leave then, but heard at 2 P.M. that she was having fits, and, on arrival in about an hour, found she was having strong convulsions at intervals of about twenty minutes. I at once gave twenty grains each of potassic bromide and chloral per rectum, and administered chloroform as soon as symptoms of a fit appeared, keeping her slightly under it in the interval. By these means the fits became less severe, and occurred at longer intervals, so that I was enabled to leave at 6 P.M. to get more drugs. The fits continued until 11 P.M., when I again resumed the chloroform, she having had another injection of bromide and chloral in the interval). The child was delivered at 12 o'clock, stillborn; and on attempting fifteen minutes later to extract the placenta, I found I was unable to do so, and on examination found the os so tightly contracted that I was unable to introduce my finger. The uterus could, however, be felt externally to be quite flaccid and dilated, and on applying pressure to it blood could be squeezed through the os as from a bag. After some minutes $I$ in- 